\title{
Applications of Finite Element Analysis and Biomechanical characteristics of cardiovascular stents
}

\author{
Y Sandeep Kumar ${ }^{1}$, N Surya Theja Yadav ${ }^{2}$ D Ramananda ${ }^{3}$ Sagar \\ ${ }^{1}$ (Assistant Professor Department of Mechanical Engineering Aditya College Of Engineering Madanapalli) \\ ${ }^{2}$ (UG Student Aditya College Of Engineering Madanapalli) \\ ${ }^{3}(U G$ Student Aditya College Of Engineering Madanapalli)
}

\begin{abstract}
The cardiovasualar diseases have become contemparary and continueosly growing problems. The main reason for such problems are the intra vessel depositions of plaque, cholesterol ect.. A traditional cure for such problems is implanting a stent. Stenting is one of the most impartent methods to treate atherosclerosis. Coronary stents are small metallic tubes in heart arteries to prevent the arteries from clossing up. Over 40 different types of stents are commercially available or in development and they are made up of stainless steel, Co-Cr alloy, plantinum, tantalum ect,. Several research papers have been published concerning stents and their properties and most of these focused on material Biocompatability and the reaction between stent and tissues. In this work mechanical properties also have to be taken into account.Coronary stent geometry was constructed from a CT scan and slices are seved as DICOM, $3 D$ doctor software was used to convert CT scan images into $3 D$ models. The model was imported into ANSYS for stress analysis. The results are drawn for two types of stents with different material properties of biocompatability materials. The results sre validated for the type 2 with Co-Cr alloy.
\end{abstract}

Keywords: CT Scan Data, Slices, 3D printing, FEA, Biocompatability

\section{Introduction}

Now a day's one of the most prevalent health problem is coronary heart disease. Coronary artery disease is specific to the carteries of the heart.Coronary heart disease which referes to the failure of the caonary circulation to provide an adequate supply of oxygenated blood to the heart. Several procedures are available to revascilarise an accluded artery. They are ballon angioplasty, stenting and bypass surgery.

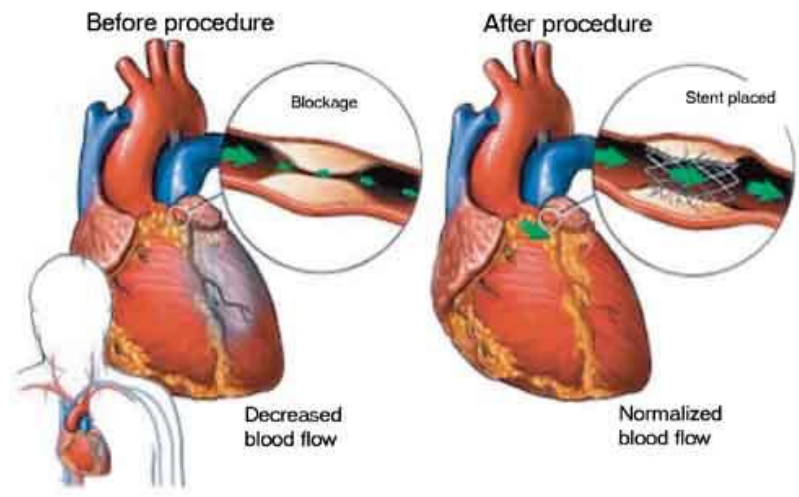

Fig 1.1: Function of cardiovascular stents

Stent implantation namely stenting does not require any surgical operation and has less complication, pain and more rapid recovery compared to the other possible treatemets. Intravasualar implants called stents are among the most impartent chievements of last years in the field of the vascular cordiology in treatement of the heart desieses. Stents are a kind of metal elastic frames with spatial cylindrical structure and of millimeter sizes that are implanted into a critical section of the coronary vessel to support its walls and to dilate its lumen.

The main reason for stent is to provide mechanical support to the artery walls. Therefore inappropriate mechanical properties could lead to complications such as damage to the artery wall. A successful implantation is depent on the good understanding of its behaviour during its development. They are two methods to analyze the behavior of stents, experimental methods and numerical simulations. Stents are commomly made up of stainless steel, nitinol, cobalt-chromiumalloys, platinum and tantalum. These are of bare metal and drug elevating ballon expandable coronary stents development has emerged as an effective treatement for coronary heart desieses. 
In 1977 Dr. Andreas Grüentzig used a catheter to insert a small balloon into a blocked coronary artery of patient Adolph Bachman. The balloon was inflated, pushing the plaque against the walls of the artery and reestablishing healthy blood flow. The patient did well after the procedure, and Grüentzig is considered a giant in the history of medical innovation. In the 1990 doctors began placing a mesh metal tube in coronary arteries during angioplasty procedures. These mesh tubes supported the arteries for the first few months required for the arteries to heal, regain strength and stay open on their own. In 2003 doctors began using drug-eluting stents. Similar to bare metal stents, these are permanent metal stents. Drug-eluting stents are coated with a medication that prevents scar tissue from forming while the coronary artery heals. The fully dissolving stent represents the fourth major evolution in angioplasty. Similar to the drug eluting stent, this treatment also called a dissolving scaffold is intended to treat coronary artery disease. But unlike earlier stents, the fully dissolving stent is made from a material that disappears as the artery heals to restore regular functioning, allowing the artery to flex and respond as needed. By the time the stent has completely dissolved, the treated segment of the artery can remain open without the extra support of the stent.

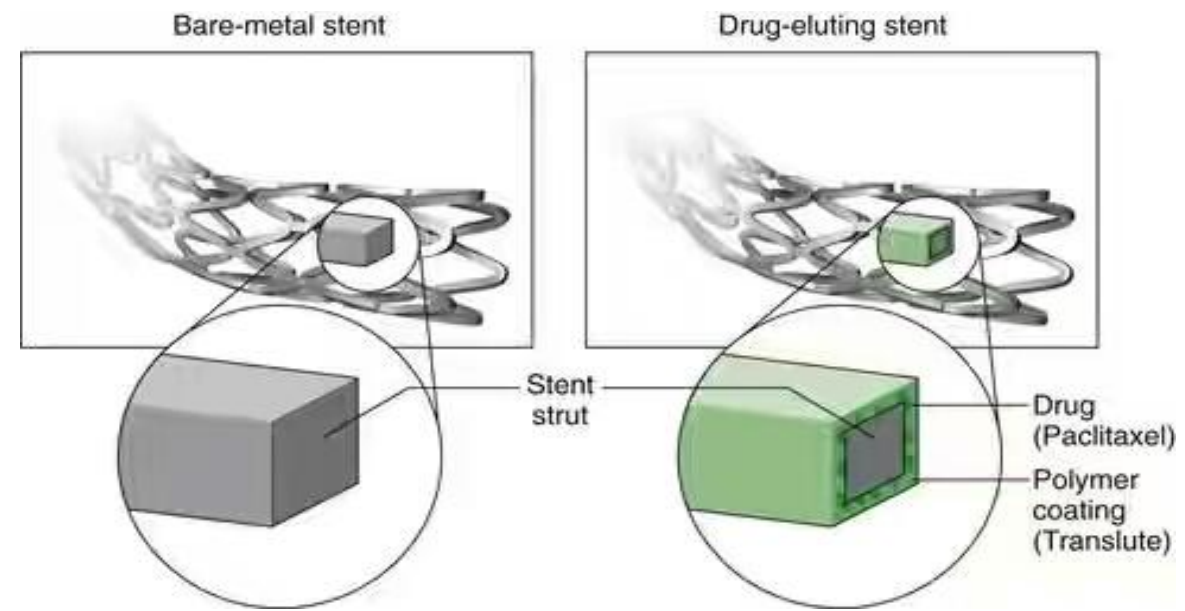

Fig 1.1: Bare metal and drug eluting stents

\section{Literature review}

Pericevic et al., Investigated several procedures are available to revascularise an occluded artery, including balloon angioplasty and stenting, bypass surgery and atherectomy. Gu et al., implanted, namely stenting, does not require any surgical operation and has less complication, pain and a more rapid recovery compared to the other possible treatments, the use of coronary stents in interventional procedures has rapidly increased in recent years. Only in the United States, 1.2 million patients undergo stent implantations each year. Chua et al., studied the restenosis rate correlates with the stress concentration in the stented vessel wall. Because of the influence of the stent design on the stress field within the artery wall, the stent design is one of the most important factors that may affect the process of restenosis after stent implantation. De Beule et al., investigated the furthermore, stent design influences the dogbone effect of stent implantation. Pericevic et al., investigated the several procedures are available to revascularise an occluded artery, including balloon angioplasty and stenting, bypass surgery and atherectomy. Chua S.N.D et al., Later on, in order to obtain better results, more complicated models have been proposed, such as balloon-stent model. Walke, W et al., Furthermore, different formulations of constitutive models for artery and plaque have been proposed in the literature, including linear isotropic.

\subsection{Modeling Of Stent:}

\section{Methodology}

It is very difficult to exactly model the stent, in which there are still researches are going on to find out stress in the stent during blood flow. Thehuman blood vessel is captured from a computerized tomography scan (CT scan) and the slices are saved as DICOM (Digital Imaging and Communications in Medicine). The 3D DOCTOR software will be used to convert CT scan images into a 3D model and the geometry. This model will be divided into quadrilateral and triangular elements by using Finite Element Analysis. The converted CT scan image (.STL) will be exported into Rapid Prototyping Machining process. The stent will be created by using FDM process. 


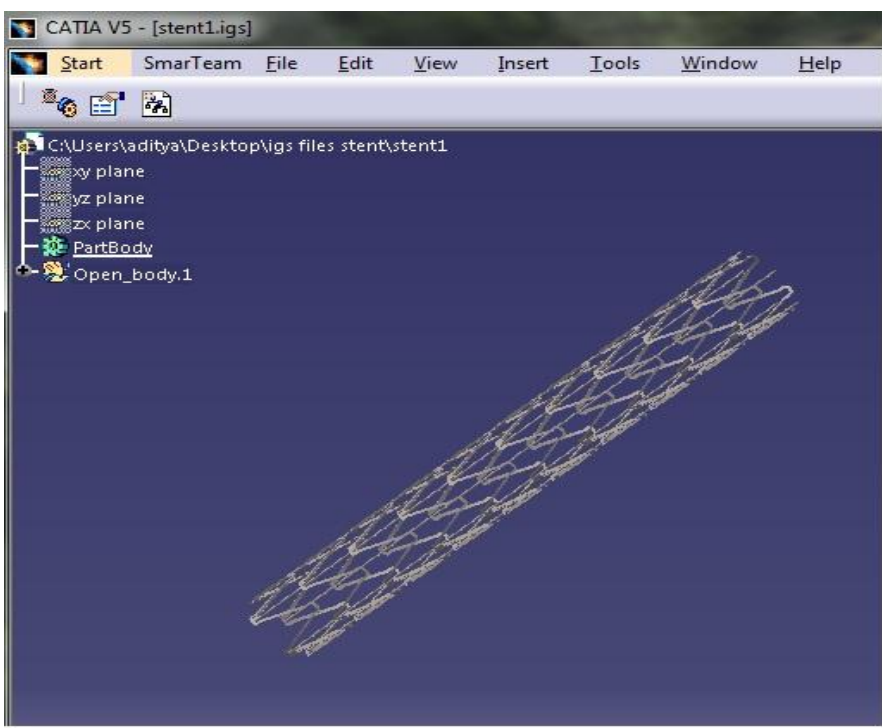

Fig 3.1: 3D model of stent design in CATIA

\subsection{Finite Elements Model of Stent:}

Fig 3.2 shows the finite element model of stent. The boundary conditions are assumed as the pressure load was applied over the inner surface of the stent having the intensity which is equal to normal blood pressure of 1-2 Mpa.Friction forces during the expansion is neglected, and the degrees of freedom is restricted on the outer surface of the stent

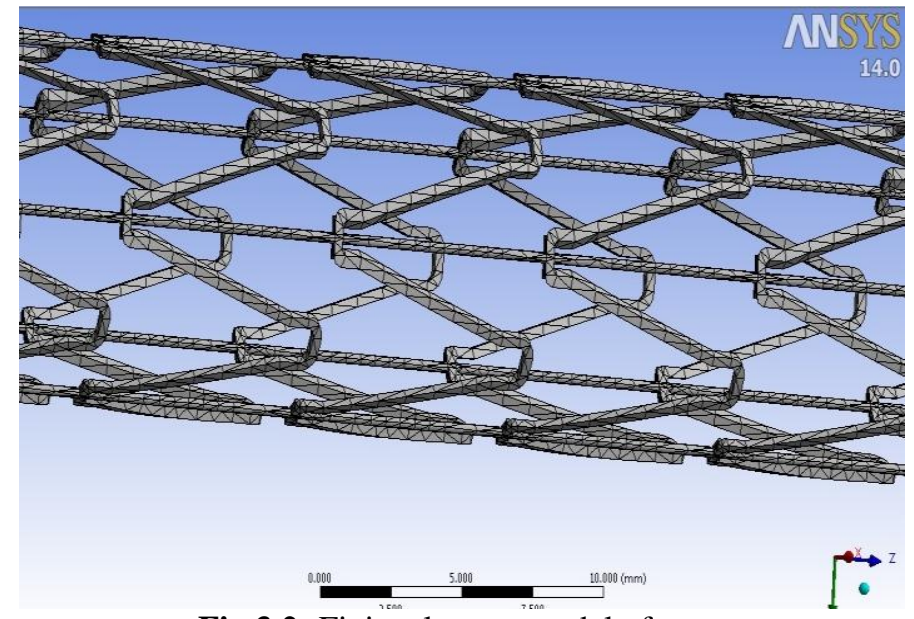

Fig 3.2: Finite element model of stent

\subsection{Stent Materials:}

\subsubsection{Stainless Steel}

Austenitic 316L stainless steel has well-suited mechanical properties making it the preferred material for stent application. Its corrosion resistance is improved by adding $2 \%-3 \%$ of $\mathrm{Mo}$, increasing the Ni content to $12 \%-15 \%$, and reducing the carbon content to less than $0.030 \%$. The surface oxide film consists of oxide species of $\mathrm{Fe}, \mathrm{Cr}, \mathrm{Ni}, \mathrm{Mo}$, and $\mathrm{Mn}$, and its thickness is about $3-4 \mathrm{~nm}$. The surface oxide changes into iron and chromium oxides when a small amount of molybdenum oxide is present in the human body.

\subsubsection{Ni-Ti Alloy (Nitinol)}

The Ni-Ti alloy, known as Nitinol, consists of roughly equal atomic amounts of $\mathrm{Ti}$ and $\mathrm{Ni}$ and shows unique mechanical properties such as shape memory, and superelasticity. Nitinol undergo plastic deformation at room temperature and crimped on to the delivery system. The transformation temperature itself is influenced by the composition, impurities, and heat treatments. Because of these unique properties, the nitinol is used for stents. Self-expanding stents have a smaller diameter at room temperature and expand to their current diameter at body temperature. 


\subsubsection{Co-Cr Alloys}

Co-Cr alloys have been used extensively in the biomedical domain. Co-Cr alloys exhibit a high density that helps to have better radiopacity, ahigh elastic modulus limiting recoil. It has also excellent wear resistance in comparison to stainless steel. For biomedical use, cast Co-Cr alloys, featured with low cast defect, known as Vitallium, resist pitting and crevice corrosion. The strength and ductility of $\mathrm{Co}-\mathrm{Cr}$ alloys are as high as those of stainless steel, after subsequent heat treatment and cold working.

\subsubsection{Platinum Alloys}

With the use of platinum alloys in stents application, both the strength and radiopacity are enhanced. Also, the need to design stents with smaller strut thickness has been achieved resulting in higher strength, using platinum-chromium based alloy.

\subsubsection{Tantalum}

Tantalum exhibits low magnetic susceptibility and high density making it outstanding X-ray imaging material. Also, Ta has excellent corrosion resistance in a biological environment because of its highly stable surface oxide layer. Ta stents have a higher possibility of breaking during deployment. Therefore, the pressure applied for the deployment of these stents is usually low and this might result in recoiling. The recoiling percentage was significantly higher for Ta stents compared with the $316 \mathrm{~L}$ stainless steel stents.

Table 3.1: Properties of different material used in stent manufacturing

\begin{tabular}{|l|l|l|l|l|l|l|}
\hline Stent material & SS 3161 & Co-Cr alloy (L605) & Nitinol & Pt-10Ir & Ta & CP-Ti \\
\hline Density $\left(\mathbf{g r} / \mathbf{C m}^{3}\right)$ & 7.95 & 9.1 & 6.45 & 21.55 & 16.6 & 4.5 \\
\hline Elastic modulus(GPa) & 193 & 243 & 90 & 150 & 185 & 107 \\
\hline
\end{tabular}

\section{Results And Discussions}

In this section, the results of the Finite Element Analysis of the cardiovascular stent are presented. This results include total deformation, radial deformation, equivalent stress and normal stress
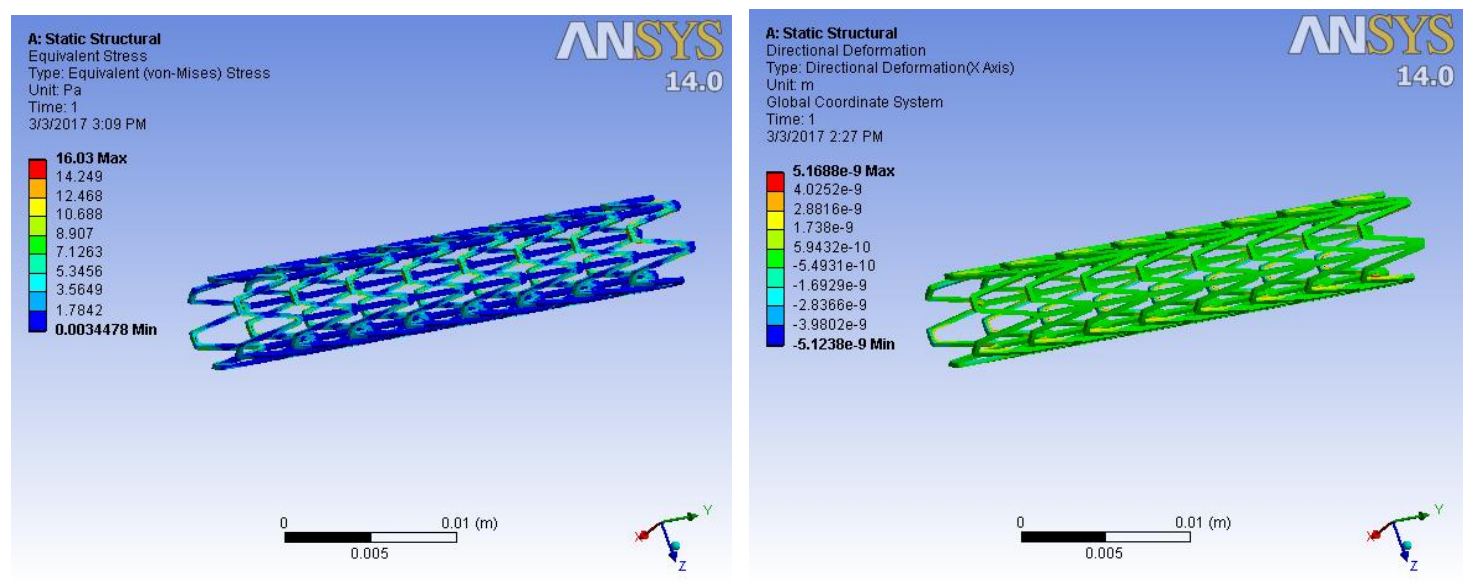

Fig 4.1: Total deformation and equivalent stress of stent

Validation Of Results

\begin{tabular}{|l|l|l|l|l|}
\hline STENT 1 & $\begin{array}{l}\text { Total Deformation } \\
(\mathbf{m m})\end{array}$ & $\begin{array}{l}\text { Directional } \\
\text { Deformation }(\mathbf{m m})\end{array}$ & $\begin{array}{l}\text { Equivalent } \\
\text { stree(MPa) }\end{array}$ & $\begin{array}{l}\text { Normal } \\
\text { Stress(MPa) }\end{array}$ \\
\hline SS316L & 0.0003989 & $3.1865 \mathrm{E}-5$ & 20.366 & 10.706 \\
\hline Co-Cr Alloy & 0.00031671 & $2.5312 \mathrm{E}-5$ & 20.352 & 10.709 \\
\hline Nitinol & 0.00085528 & $6.8338 \mathrm{E}-5$ & 20.359 & 10.708 \\
\hline Pt-10Ir & 0.00051317 & $4.1003 \mathrm{E}-5$ & 20.359 & 10.708 \\
\hline Ta & 0.00041608 & $3.3245 \mathrm{E}-5$ & 20.359 & 10.708 \\
\hline Cp-Ti & 0.00071939 & $5.748 \mathrm{E}-5$ & 20.359 & 10.708 \\
\hline
\end{tabular}

\begin{tabular}{|l|l|l|l|l|}
\hline STENT 2 & $\begin{array}{l}\text { Total Deformation } \\
(\mathbf{m m})\end{array}$ & $\begin{array}{l}\text { Directional } \\
\text { Deformation (mm) }\end{array}$ & $\begin{array}{l}\text { Equivalent } \\
\text { stree(MPa) }\end{array}$ & $\begin{array}{l}\text { Normal } \\
\text { Stress(MPa) }\end{array}$ \\
\hline SS316L & 0.00030849 & $6.5706 \mathrm{E}-9$ & 16.025 & 4.3456 \\
\hline Co-Cr Alloy & $\mathbf{0 . 0 0 0 2 4 5 0 2}$ & $\mathbf{5 . 1 6 8 8 E - 9}$ & $\mathbf{1 6 . 0 3}$ & $\mathbf{4 . 3 3 1 9}$ \\
\hline Nitinol & 0.00066156 & $1.3956 \mathrm{E}-8$ & 16.03 & 4.3319 \\
\hline Pt-10Ir & 0.00039694 & $8.3735 \mathrm{E}-9$ & 16.03 & 4.3319 \\
\hline Ta & 0.00032183 & $6.789 \mathrm{E}-9$ & 16.03 & 4.3319 \\
\hline Cp-Ti & 0.00055646 & $1.1739 \mathrm{E}-8$ & 16.03 & 4.3319 \\
\hline
\end{tabular}




\section{Conclusion}

This paper presents a methodology for modeling the expansion of coronary stents used in the treatment of blood vessel.A commercially available stent models was analysed in this study. The analysis performed and the results obtained could be used in design and optimization of geometrical and material properties of the stent. From the comparison table we can say that all the values obtained from the analysis it is concluded that model 2 having $\mathrm{Co}-\mathrm{Cr}$ alloy is the best possible for the present application So the optimum result to minimize the deformation and stress values while the model-2 stent having $\mathrm{Co}-\mathrm{Cr}$ alloy material.

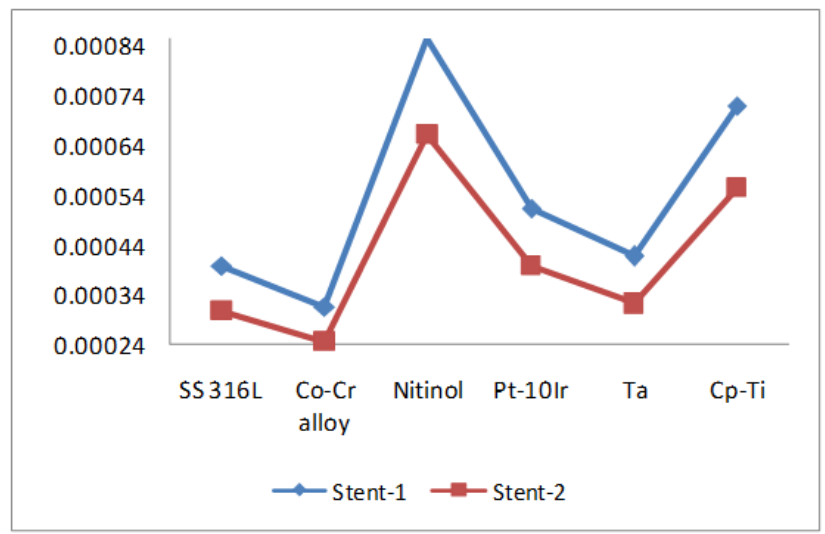

Graph 6.1: Total deformation

\section{Acknowledgements}

We would like to thank to VVN Bhaskar HOD, Dept of ME, Dr. S. Ramalinga Reddy Principal, Aditya College of Engineering Madanapalle for precious support for giving access to the laboratory and research facilities.Last but not least our sincere thanks also goes to IOSR Journal for recognizing our work.

\section{References}

[1]. Pericevic, I., C. Lally, D. Toner and D.J. Kelly, 2009 "The influence of plaque composition on underlying arterial wall stress during stent expansion: The case of lesion-specific stents" Med. Eng. Phys., 31: 428-433.

[2]. Gu, L., S. Zhao, A.K. Muttyam and J.M. Hammel, 2010 "The relation between the arterial stress and restenosis rate after coronary stenting “

[3]. Chua S.N.D., MacDonald B.J., Hashmi M.S.J., 2002 “Finite-element simulation of stent expansion”, Journal of Materials Processing Technology, 120, 335-340

[4]. De Beule M., Van Impe R., Verhegghe B., Segers P., Verdonck P., 2006 "Finite element analysis and stent design- Reduction of dogboning", Technology and Health Care, 14, 233-241

[5]. Walke, W., Z. Paszenda and J. Filipiak, 2005 "Experimental and numerical biomechanical analysis of vascular stent". J. Mater. Process. Technol., 164-165: 1263-1268

[6]. Dumoulin C., Cochelin B., 2000, "Mechanical behaviour modelling of balloon-expandable stents," Journal of Biomechanics, 33, 1461-1470 11.

[7]. Gervaso F., Capelli C., Petrini L., Lattanzio S., Di Virgilio L., Migliavacca F., 2008,"On the effects of different strategies in modelling balloon-expandable stenting by means of finite element method", Journal of Biomechanics, 41, 1206-1212

[8]. Kastrati A., Dirschinger J., Boekstegers P., Elezi S., Schuhlen H., Pache J., et al., 2000, "Influence of stent design on 1-year outcome after coronary stent placement: A randomized comparison of five stent types in 1147 unselected patients, Catheterization and Cardiovascular Interventions, 50, 290-297

[9]. Lansky A.J., Roubin G.S., O’Shaughnessy C.D., Moore P.B., Dean L.S., Raizner A.E., et al., 2000, "Randomized comparison of GR-II stent and Palmaz-Schatz stent for elective treatment of coronary stenoses, Circulation", 102, 1364-1368 21.

[10]. Marion C.D., Karvouni E., 2000, “The bigger, the better: true also for in-stent restenosis," European Heart Journal, 21, 710-711.

[11]. Walke W., Paszenda Z., Filipiak J., 2005, "Experimental and numerical biomechanical analysis of vascular stent", Journal of Materials Processing Technology, 164/165, 1263-1268 29.

[12]. Wang W.Q., Liang D.K., Yang D.Z., Qi M., 2006, "Analysis of the transient expansion behavior and design optimization of coronary stents by finite element method", Journal of Biomechanics, 39, 21-32

\section{BIO-GRAPHY:}

Mr. Y Sandeep Kumar, Assistant Professor in Department of mechanical Engineering Aditya College of

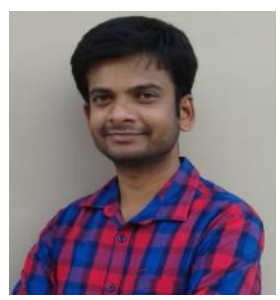
Engineering Madanapalle. He received the bachelor's degree in mechanical engineering and Master's degree in CAD/CAM from JNTU and Pursuing PhD from Visweswaraya Technological University Belagavi. He has 5 years of teaching experience. His research interests include Bio materials, Biomechanical Analysis and Finite Element Analysis. He published more than 10 papers in International and National Journals and conferences. 
Mr. N Surya Theja Yadav doing bachelor's degree in Mechanical Engineering from JNTU University

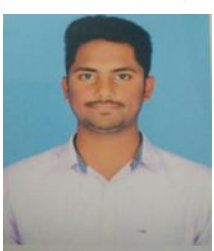
Anantapur in Aditya college of Engineering Madanapalle.

Mr. D Ramananda ${ }^{3}$ Sagar doing bachelor's degree in Mechanical Engineering from JNTU University Anantapur in Aditya college of Engineering Madanapalle.. 